\title{
Brain Perfusion Imaging in Neonates: An Overview
}

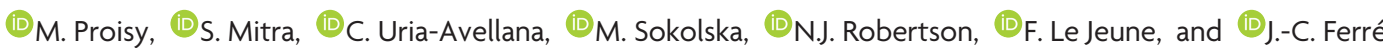

\section{ABSTRACT}

SUMMARY: The development of cognitive function in children has been related to a regional metabolic increase and an increase in regional brain perfusion. Moreover, brain perfusion plays an important role in the pathogenesis of brain damage in high-risk neonates, both preterm and full-term asphyxiated infants. In this article, we will review and discuss several existing imaging techniques for assessing neonatal brain perfusion.

ABBREVIATIONS: $A$ SL $=$ arterial spin-labeling; HIE = hypoxic-ischemic encephalopathy; NIRS $=$ near-infrared spectroscopy

B rain perfusion can be assessed by a number of imaging techniques that have been developed in recent decades. These include PET, SPECT, perfusion CT, diffuse optical spectroscopy, DSC-MR imaging, arterial spin-labeling (ASL), and sonography. The physiology of perfusion can be characterized by many parameters such as $\mathrm{CBF}$ (whole-brain or regional CBF to $\geq 1$ anatomic region), CBV, and MTT. Some of these parameters may be obtained depending on the perfusion technique and type of tracer used. ${ }^{1}$ The results of brain perfusion imaging techniques are usually expressed as CBF. Most of these techniques rely on the use of endogenous or exogenous tracers and involve different technical requirements and mathematic models. ${ }^{2-4}$ Wintermark et $\mathrm{al}^{5}$ published a literature review of brain perfusion imaging techniques in adults and addressed the feasibility of applying the techniques to children. However, in view of the features of neonatal physiology and pathology, the advantages and disadvantages may differ between adults and children. For example, bedside techniques are an advantage for high-risk neonates. Noninvasive and nonradiating

From the Department of Radiology (M.P., J.-C.F.), Rennes University Hospital, France; Department of Neonatology (M.P., S.M., C.U.-A., N.J.R.), University College London Hospital, Institute for Women's Health, University College of London, London, UK; Inserm VisAGeS Unit U746 (M.P., J.-C.F.), Inria, Rennes 1 University, Rennes, France; Institute of Neurology (M.S.), University College of London, London, UK; and Department of Nuclear Medicine (F.L.J.), Centre Eugène Marquis, Rennes, France.

This work was performed with the support of the Société Française de Radiologie (2012 Research Grant).

Please address correspondence to Maïa Proisy, MD, Department of Radiology, Pediatric Imaging, Rennes University Hospital, 16 Boulevard de Bulgarie, BP 90347 , 35203 Rennes Cedex 2, France; e-mail: maia.proisy@chu-rennes.fr

- Indicates open access to non-subscribers at www.ajnr.org

三 Indicates article with supplemental on-line table.

http://dx.doi.org/10.3174/ajnr.A4778 methods that have been recently developed owing to advances in medical imaging techniques are highly suitable for neonates. ${ }^{6,7}$ However, given the smaller head size and lower physiologic brain perfusion compared with older children and adults, noninvasive MR perfusion imaging is still challenging.

Neonatal encephalopathy secondary to hypoxic-ischemic injury around birth is an important problem worldwide. Diagnosis is based on clinical, electroencephalographic, and MR imaging findings. Hypoxic-ischemic encephalopathy (HIE) is a major cause of perinatal mortality and morbidity. ${ }^{8}$ For a few years, induced hypothermia has been used as neuroprotective treatment for neonatal HIE, reducing the extent of neurologic damage and improving outcome. ${ }^{9,10}$ However, a considerable number of infants still have an abnormal outcome. Several preclinical research studies are also being conducted on drugs that may act synergistically or additively with hypothermia. ${ }^{11,12}$ Transfontanellar ultrasound and MR imaging provide invaluable information about neonates with HIE for determining positive findings and differential diagnoses, predicting neuromotor outcome, and helping to counsel parents about long-term outcome. ${ }^{13}$ Moreover, MRI is an effective biomarker for treatment response. ${ }^{14}$ In addition to conventional MR imaging scoring, ${ }^{15}$ some quantitative biomarkers could provide more objective information, such as DWI with regional ADC measurements, ${ }^{16}{ }^{1} \mathrm{H}-\mathrm{MR}$ spectroscopy, and ${ }^{31} \mathrm{P}$ MR spectroscopy. ${ }^{17}$

Brain perfusion plays an important role in the pathogenesis of brain damage in high-risk neonates, both preterm and full-term asphyxiated neonates. ${ }^{18,19}$ Hypoxic-ischemic injury leads to reduced blood flow to the brain followed by restoration of blood flow and the initiation of a cascade of pathways. The neurotoxic biochemical cascade of lesions after reperfusion, known as "reperfusion injury," is the primary target for neuroprotective inter- 
ventions. ${ }^{10,12}$ In preterm infants, white matter injury is a major cause of cerebral palsy, which is also assumed to be mainly due to a lack of blood flow and oxygen delivery. ${ }^{20}$

It is critical to understand the development of early changes in the injured neonatal brain. A better understanding of the pattern of perfusion and the relationship with other therapeutic and outcome biomarkers would serve as a decision aid to improve support for high-risk neonates.

In this article, we will review and discuss several existing imaging techniques for assessing neonatal brain perfusion (On-line Table).

\section{Practical Aspects of Data Acquisition in Neonates}

There is no consensus regarding the practical aspects of data acquisition, and each institution may have its own practice. Often, infants younger than 3 months of age are imaged without sedation unless they are receiving sedative medication for clinical indications. We use the "feed and bundle" method to perform nonsedated neonatal MR imaging. Ventilated infants in the intensive care unit are usually sedated with morphine. Moreover, depending on the clinical condition, additional drugs may be given, antiepileptic drugs or vasopressors. In infants older than 3-5 months of age, sedation may be required. Sedation status remains an important consideration in pediatric imaging. Indeed, sedation may have an impact on cerebral perfusion. There are few data in the literature about how sedation or general anesthesia may alter perfusion. $^{21,22}$

Without sedation, a rigid head stabilization (head lightly fixed) is required to perform most imaging (MR imaging, PET, SPECT, CTP). The longer the examination, the longer the immobilization is required. Near-infrared spectroscopy (NIRS) does not require rigid head stabilization because the optical fibers are embedded in a "cap" attached to the infant's head.

\section{Brain Perfusion Measurements by Using Nuclear Medicine Methods}

Nuclear medicine methods were the first ones used to assess CBF in adults and neonates. ${ }^{23,24}$ Correlation with structural information (CT or MR imaging) is highly desirable for accurate interpretation.

Positron-Emission Tomography. The PET technique measures radiopharmaceuticals labeled with positron emitters using a PET scanner. PET is used to assess regional CBF by using injected $\mathrm{H}_{2} \mathrm{O}$ or inhaled $\mathrm{CO}_{2}$ labeled with the isotope oxygen $15\left({ }^{15} \mathrm{O}\right)$. PET with ${ }^{15} \mathrm{O}$ water provides an accurate and reproducible quantitative measurement of $\mathrm{CBF}$ and is considered the criterion standard method. However, ${ }^{15} \mathrm{O}$-PET uses ionizing radiation, and the technique is not widely available (there is a need for close proximity to a cyclotron) because the tracer has an extremely short half-life. Moreover, PET is not available at the bedside or for emergencies. Data processing to obtain maps is automatically generated by the workstation; then the results can be visually interpreted on a computer screen. The underlying mathematic model for data postprocessing is the Kety-Schmidt model. ${ }^{5}$

In 1983, Volpe et $\mathrm{al}^{23}$ conducted the first study demonstrating the use of PET for determining regional CBF in neonates. Altman et $\mathrm{al}^{25}$ measured mean CBF in 16 preterm infants $(\mathrm{CBF}=4.9-23$
$\mathrm{mL} / 100 \mathrm{~g} / \mathrm{min}$ ) and 14 term infants $(\mathrm{CBF}=9.0-73 \mathrm{~mL} / 100$ $\mathrm{g} / \mathrm{min}$ ). Volpe et $\mathrm{al}^{18}$ studied regional CBF in 17 asphyxiated term infants during the acute stage of their illness and showed a symmetric decrease in CBF to the parasagittal regions, more marked posteriorly than anteriorly. Those findings explain the ischemic lesions related to impaired cerebral perfusion in the watershed regions.

PET by using ${ }^{18} \mathrm{~F}$-fluorodeoxyglucose evaluates the regional cerebral metabolic rate (Fig 1). In neonates, the highest cerebral metabolic rates for glucose are located in the primary sensorimotor cortex, thalamus, brain stem, and cerebellar vermis. The cingulate cortex, basal ganglia, and hippocampal regions may also have a relatively high glucose metabolism compared with most of the cerebral cortex. ${ }^{26}$ A recent study conducted on 60 infants, including 24 infants with $\mathrm{HIE},{ }^{27}$ showed that cerebral glucose metabolism increased with gestational age and that the standardized uptake values were lower in infants with HIE than in healthy term infants, especially in the subcortical white matter, thalamus, and basal ganglia areas, and correlated with the degree of severity of HIE, except for the basal ganglia. Batista et $\mathrm{al}^{28}$ suggested that there is a transient increase in glucose metabolism in the basal ganglia after perinatal hypoxia and that it may be associated with excess glutamatergic activity in the basal ganglia, leading to severe damage.

Single-Photon Emission CT. SPECT provides tomographic images of radiopharmaceutical distribution. It involves the inhalation or intravenous injection of xenon $133\left({ }^{133} \mathrm{Xe}\right)$, with technetium Tc99m hexamethylpropyleneamine oxime $\left({ }^{99 \mathrm{~m}} \mathrm{Tc}-\right.$ HMPAO) or iodine $123 \mathrm{~N}$-isopropyl-p-iodoamphetamine $\left({ }^{123}\right.$ I-IMP). Due to neonatal brain physiology and biodistribution, HMPAO is a more reliable tracer of CBF distribution in neonates compared with adults. ${ }^{29}$

SPECT is a suitable bedside method that is cheaper and more widely available than PET imaging. HMPAO and IMP only show distribution and do not provide quantitative results, unlike xenon. The greatest disadvantage in using the SPECT technique in children is the ionizing radiation. The technique also yields poor resolution and requires a long examination time (20-25 minutes). Data processing to obtain maps takes about 5 minutes. The underlying mathematic model for data postprocessing is the Kety-Schmidt model for the ${ }^{133} \mathrm{Xe}$ and ${ }^{123}$ I-IMP or the microsphere principle for the Tc99m tracers. Because the uptake of ${ }^{99 m} \mathrm{Tc}-\mathrm{HMPAO}$ is not linearly related to $\mathrm{CBF}$, the maps obtained are not quantitative in the current standardized settings and require special correction. The relative CBF maps can be statistically evaluated compared with the healthy control to depict the regions with abnormal perfusion. ${ }^{5}$

Xenon clearance, by using inhaled xenon gas, is another technique that is closely related to SPECT and has been extensively used in adults and neonates. ${ }^{30}$ Patient motion is a serious limitation of the technique, which, moreover, does not cover the whole brain. The mean CBF with the xenon technique has been estimated at around $50 \mathrm{~mL} / 100 \mathrm{~g} / \mathrm{min}$ in 7 healthy neonates ${ }^{31}$ and 9.5-11.7 $\mathrm{mL} / 100 \mathrm{~g} / \mathrm{min}$ in 22 preterm infants during the first 3 days of life. ${ }^{32}$ Changes in ${ }^{123}$ I-IMP uptake in neonates reflecting relative $\mathrm{CBF}$ during the first month of life have been shown to be related to myelination development. ${ }^{33}$ In term neonates, up- 


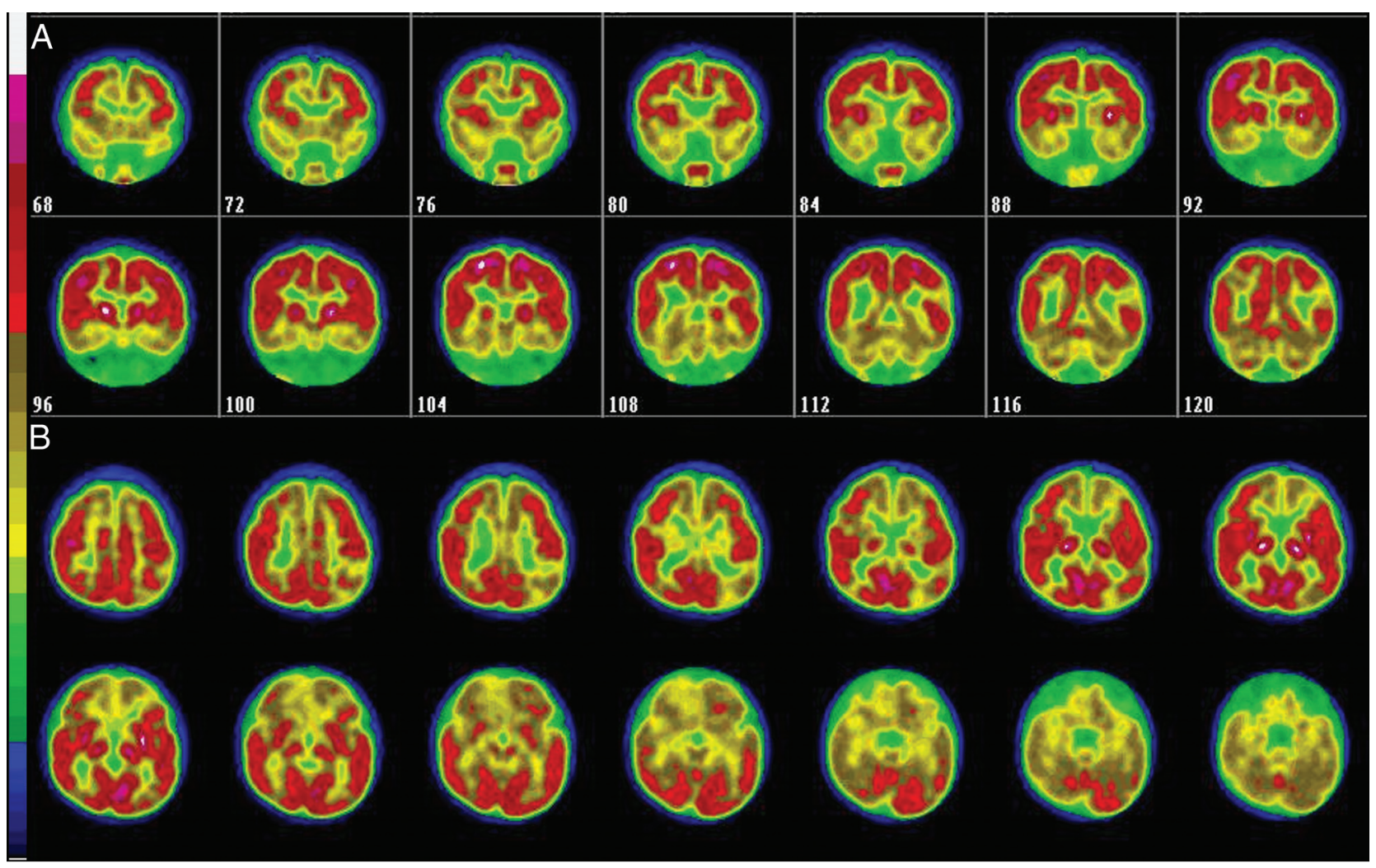

FIG 1. Coronal $(A)$ and axial $(B)$ cerebral ${ }^{18}$ F-FDG PET images of a 9-month-old infant with tuberous sclerosis show multiple hypometabolic areas in the frontal and temporal cortex. Courtesy of Prof. Eric Guedj, CHU Timone, Marseille, France.

take was predominantly located in the thalami, brain stem, and central cerebellum, with relatively less cortical activity, except in the perirolandic cortex. Moreover, Pryds and Greisen ${ }^{32}$ showed that an intraindividual variation in CBF was positively related to changes in partial pressure of carbon dioxide in arterial blood and inversely related to changes in hemoglobin concentration.

\section{Brain Perfusion Measurements by Using Perfusion CT}

Perfusion CT has been widely used in adults and can be performed easily and rapidly. This technique provides a reliable quantitative estimation of CBF, CBV, and MTT by using a first-pass tracer methodology after intravenous injection of a bolus of iodinated contrast material. It involves very rapid data acquisition that is feasible in emergency situations. ${ }^{34,35}$ However, due to its invasive nature and radiation dose, very few studies have included neonates. Data processing requires perfusion CT software using either rate-of-upslope estimation of CBF or deconvolution analysis. ${ }^{5}$ Images of CBF, CBV, and MTT maps are interpreted on a workstation with visual assessment and quantitative analysis with ROIs. Wintermark et $\mathrm{al}^{36}$ assessed age-related variations in quantitative brain perfusion CT in children from 7 days to 18 years of age without brain abnormality, including 10 patients younger than 12 months of age. The rCBF findings were consistent with other techniques and showed age-specific variations with a peak at 2-4 years of age. The variation in CBF estimates was due to more pronounced age-related changes in MTT than in CBV.

\section{Brain Perfusion Measurements by Using Near-Infrared Spectroscopy}

Near-infrared spectroscopy, described first by Jöbsis in $1977,{ }^{37}$ can be used as a continuous noninvasive real-time monitoring tool for assessment of cerebral oxygenation and hemodynamics. The principles of NIRS are based on the relative transparency of biologic tissues to light in the near-infrared spectrum (700-1000 $\mathrm{nm}$ ) and different absorption of light by different chromophores in this spectrum (eg, hemoglobin and cytochrome C oxidase). NIRS measures the concentration changes of oxy- and deoxyhemoglobin, which can be used to derive changes in total hemoglobin (an indicator of cerebral blood volume) and hemoglobin difference (indicates cerebral oxygenation). ${ }^{38}$ Using spatially resolved spectroscopy, NIRS measures regional oxygenation saturation and reflects the balance of tissue oxygen supply and demand. In comparison with other techniques, application of NIRS is relatively easier. Improved NIRS probes are now available in different sizes to cover premature infants to term neonates. Although NIRS monitors have been used in adult neurointensive care units and theaters for some time now, the introduction of these monitors into neonatal intensive care has been slow. In recent years, several NICUs have started using this as part of the routine decision-making process, particularly for the preterm population.

Edwards et $\mathrm{al}^{39}$ first described the measurement of cerebral blood flow, and Meek et $\mathrm{al}^{40}$ showed that low CBF on the first day of life is a risk factor for severe intraventricular hemorrhage. Diffuse correlation spectroscopy is a newer NIRS tech- 

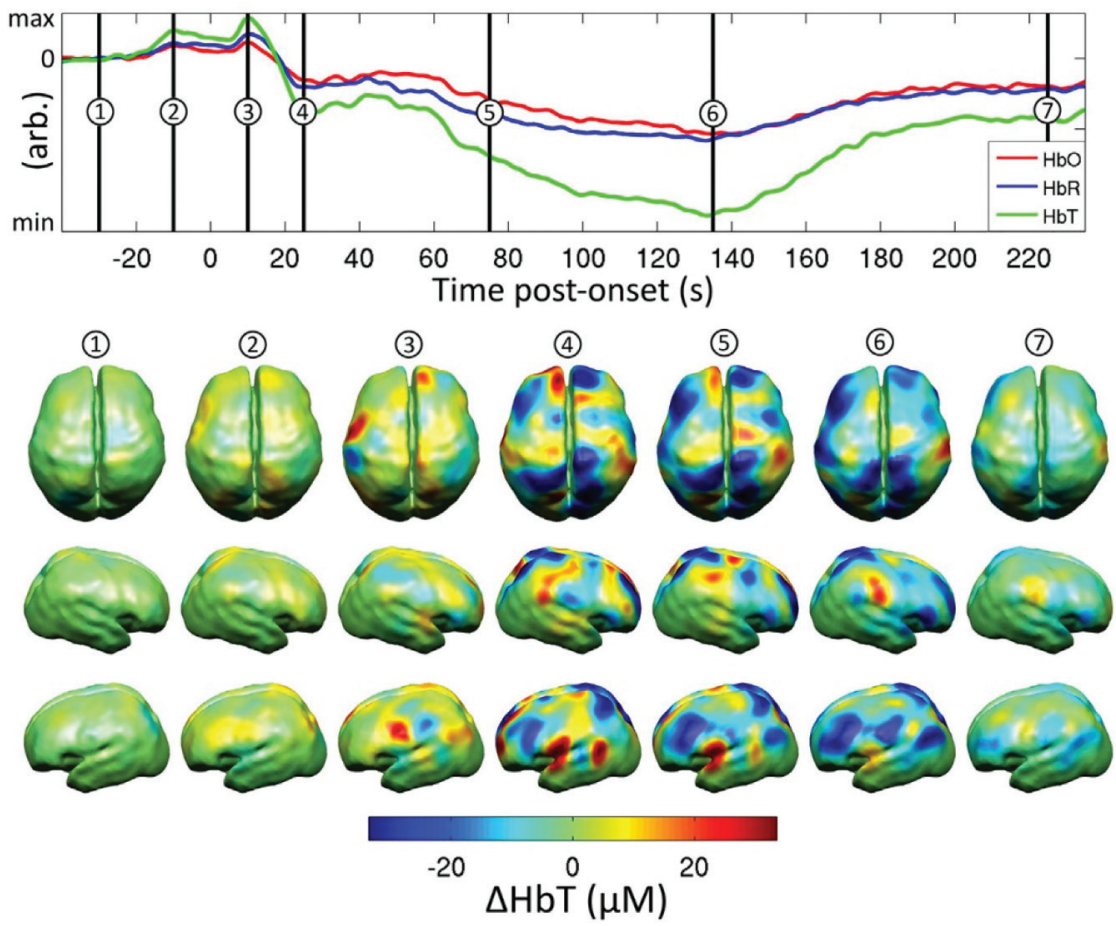

FIG 2. Reconstructed images showing the changes in cerebral blood volume $(\Delta \mathrm{HbT})$ in the dorsal and left and right lateral views during a seizure in a neonate with hypoxic-ischemic encephalopathy. The upper axes show the changes in hemoglobin concentration spatially averaged across the gray matter surface. Seven distinct time points are identified. All data are changes relative to a baseline, defined as the mean of the period between 60 and 30 seconds before the electrographic seizure onset. Reproduced from Singh et al. ${ }^{48}$

nique that offers a direct and continuous monitoring of microvascular cerebral blood flow. ${ }^{41}$ Using hemoglobin difference as an indicator of CBF, Tsuji el $\mathrm{al}^{42}$ described a high coherence between $\mathrm{CBF}$ and mean arterial blood pressure and a strong association of the loss of cerebral autoregulation with an increased incidence of severe germinal matrix-intraventricular hemorrhage or periventricular leukomalacia. The loss of autoregulation in the very preterm population was strongly related to mortality. ${ }^{43}$

Following perinatal hypoxia-ischemia in term infants, CBF and CBV were elevated and were associated with low oxygen extraction and the loss of reactivity to $\mathrm{CO}_{2} \cdot{ }^{44}$ This loss of the autoregulatory mechanism with loss of cerebrovascular tone happens during the first 24 hours after the insult before secondary energy failure ensues. In a recent study, regional oxygenation saturation increased and fractional tissue oxygen extraction decreased after 24 hours in 18 neonates with poor outcome following HIE. ${ }^{45}$ High tissue oxygenation values were noted on day 1 following perinatal hypoxia and were significantly higher in the group with abnormal 1-year outcome. ${ }^{46}$ These findings were further supported by a combined NIRSASL study ${ }^{47}$ : a strong correlation was noted between NIRSmeasured regional cerebral oxygen saturation and CBF measured by ASL in infants with severe encephalopathy. Specific changes in cortical hemodynamics and oxygenation were described in previous NIRS studies during and after neonatal seizures (Fig 2). ${ }^{48}$

\section{Brain Perfusion Measurements Using Sonography}

Kehrer et $\mathrm{al}^{49,50}$ have shown the feasibility of measuring CBF volume with Doppler sonography of the extracranial cerebral arteries in infants. Another way to assess overall $\mathrm{CBF}$ is to measure the total blood flow to the brain (sum of blood flow in the internal carotid arteries and basilar artery) and to divide it by the brain volume. Doppler sonography is noninvasive, lacking radiation exposure, innocuous, and suitable for bedside follow-up and has good interobserver reproducibility. ${ }^{51}$ However, the disadvantages include the absence of regional CBF measurements, the use of an estimated brain weight, the need for the patient to be motionless for about 20 minutes, and strict compliance with a standardized study protocol/meticulous examination to achieve accurate and reliable measurements. ${ }^{50}$ In healthy term neonates, the velocities in the ICAs and basilar artery are between 15 and 35 $\mathrm{cm} / \mathrm{s} .{ }^{52}$ As shown with other techniques, the values of $\mathrm{CBF}$ volume increased with postmenstrual age from $33 \mathrm{~mL} / \mathrm{min}$ at 34 weeks to $85 \mathrm{~mL} / \mathrm{min}$ at 42 weeks. ${ }^{49}$ Approximate CBF (mL/100 g/min) was calculated by using an estimated brain weight (the equation was based on head circumference measurements). CBF also increases from 21 to $23 \mathrm{~mL} / 100$ $\mathrm{g} / \mathrm{min}$ after birth to $46-53 \mathrm{~mL} / 100 \mathrm{~g} / \mathrm{min}$ at 6 months of age and remains stable from 6 to 30 months of age, reflecting rising metabolic demand. ${ }^{53}$

Microbubble ultrasound is a new and reliable cerebral perfusion imaging technique that provides a qualitative estimation of cerebral perfusion and has been described in healthy adults and patients with stroke. ${ }^{54}$ Yet, to our knowledge, no study has been conducted on neonates, mainly because microbubble ultrasound is not licensed for use in children.

\section{Brain Perfusion Measurements by Using MR Imaging}

Regarding practical aspects of MR imaging, one of the main advantages is that perfusion imaging is a part of the whole examination. The perfusion sequence could be added at the end of the morphologic MR imaging, which is usually clinically required.

Dynamic-Susceptibility Contrast MR Imaging. The dynamic-susceptibility contrast MR imaging technique measures the T2 or $\mathrm{T} 2{ }^{*}$ decrease during the first pass of an exogenous endovascular susceptibility contrast agent. DSC-MR imaging is a nonradiating procedure, with high SNR and a higher spatial resolution than PET and SPECT, in addition to offering fast acquisition times. Regional hemodynamic changes can be assumed and different parameters such as CBV, TTP, and MTT can be estimated to calculate CBF. Parameters are calculated in a few minutes 


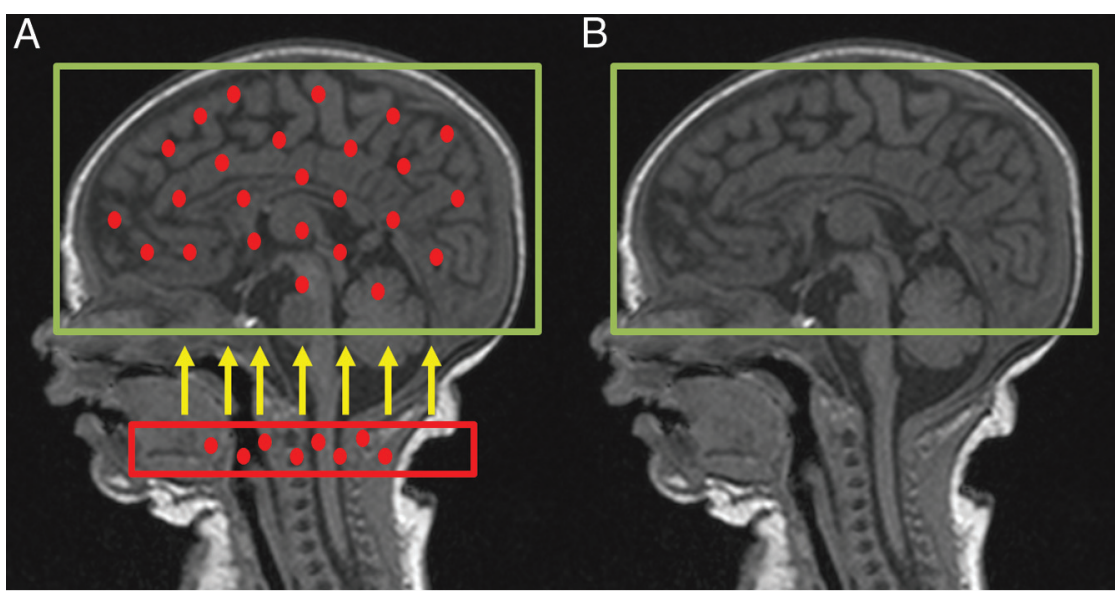

FIG 3. Schematic diagram of ASL shows the labeling plane (red box) in the neck and the imaging volume (green box). A, Acquisition of labeled image after a delay to allow the labeled blood to flow into the brain tissue. $B$, Acquisition of the control image.

by using commercially available software. However, the maps provide only relative measurements. Quantification of CBF by DSC is controversial, mainly due to the nonlinear relationship between signal intensity and gadolinium concentration. ${ }^{55}$ Maps can be interpreted visually or semiquantitatively by calculating the ratio between the values in an ROI placed in the abnormal area and an ROI placed in the contralateral area considered a normal reference. Longitudinal studies involving repeated measurements during a single scanning session are not possible due to the lack of reliable absolute quantification. Despite the above-mentioned advantages, DSC-MR imaging can be difficult to perform in infants due to gadolinium administration. There have been fewer studies of DSC-MR imaging in children, and particularly neonates, than in adults. ${ }^{56-59}$ Hand injections are preferred over power injections in infants, with less reproducibility. Wintermark et $\mathrm{al}^{58}$ were the first to assess PWI in 5 term neonates with HIE on early (days 2-4) and late MR imaging (days 9-11). On the early MR imaging, a hyperperfusion pattern was detected in areas of hypoxic-ischemic brain damage, corresponding to the reperfusion phase. On the late scans, hyperperfusion persisted in the cortical gray matter.

Phase-Contrast MR Imaging. One other noninvasive, accurate, and reproducible MR imaging method has been reported in a small number of studies. ${ }^{60,61}$ The blood flow in the internal carotid arteries and basilar artery at the base of the skull is measured by using phase-contrast MR imaging, and the brain volume is measured by using segmentation of anatomic MR images. Data processing consists of multiplying the mean velocity across an ROI (measured by the phase-contrast MR imaging sequence) by the vessel area. Flow to the brain is computed as the sum of flow in the 2 internal carotid arteries and the basilar artery. Brain volume is estimated by using segmentation software by using a dedicated neonatal brain segmentation algorithm. Mean CBF is computed by dividing the total flow to the brain by the brain volume.

In the study by Varela et al, ${ }^{60}$ the results for 21 infants showed good agreement with literature data, with a rapid increase during the first year of life, from $25-60 \mathrm{~mL} / 100 \mathrm{~mL}$ of tissue/min. The mean velocities (over the cardiac cycle, the area of each vessel and all 3 arteries) were $<20 \mathrm{~cm} / \mathrm{s}$ in term neonates and rose to $30 \mathrm{~cm} / \mathrm{s}$ at 50 weeks. However, only mean overall CBF can be assessed with this method.

Arterial Spin-Labeling. Brain perfusion imaging by using arterial spin-labeling is a noninvasive technique that uses endogenous blood water as a freely diffusible tracer. Arterial blood protons are magnetically labeled with a radiofrequency inversion pulse applied below the imaging section in the neck vessels (Fig 1). Several labeling methods exist, including continuous ASL, pulsed ASL, and pseudocontinuous ASL. ${ }^{62}$ In continuous ASL, a long flow-induced inversion pulse is applied. In pulsed ASL, a short inversion pulse is applied to a larger region of the neck. Pseudocontinuous ASL is a hybrid method that uses a train of short radiofrequency pulses to mimic the effects of continuous ASL (Fig 3). The best recommended ASL method is the pseudocontinuous ASL labeling method, mainly because of a higher SNR and less labeling artifacts. ${ }^{63,64}$ However, there is a lack of data in the literature regarding the specific neonatal population, and more study is needed.

A labeled image is acquired after a sufficient time to allow the labeled spins to reach the imaging section, known as the postlabeling delay. A control image is acquired without labeling. Subtraction of the 2 images yields a perfusion-weighted image. Because the signal difference is only $0.5 \%-1.5 \%$ of the full signal, multiple repetitions are needed to improve the signal-to-noise ratio. Subsequently, to obtain a quantitative perfusion map, a quantitative model is required to calculate the relationship between the perfusion-weighted image and CBF.

Certain technical adjustments to the imaging parameters are required to account for the fundamental differences between the pediatric and adult populations. ${ }^{65,66}$ It is challenging to perform ASL MR imaging in neonates due to the low baseline CBF compared with children and adults, coupled with the low SNR of the method. As an example, velocities are lower in neonates than in children, increasing with postmenstrual age, ${ }^{67}$ and the optimum postlabeling delay for contrast-to-noise ratio has been correlated with the mean velocity in the carotid arteries. ${ }^{68}$

Moreover, in children and neonates, there is a physiologic improvement in the SNR compared with healthy adults due to a longer tissue T1, longer blood T1, and the higher blood-brain partition coefficient of water. ${ }^{65}$ Blood $\mathrm{T} 1$ variations have a greater effect on perfusion than tissue T1 variations. ${ }^{69}$ Varela et $\mathrm{al}^{70}$ established a linear correlation between the inverse of blood T1 and hematocrit in 12 neonates. This may offer the possibility of blood T1 estimations from recent hematocrit measurements.

Measuring CBF in neonates by using ASL therefore requires several adaptations of acquisition and related parameters used for quantification. Another point is the lack of standardization of image-processing methods. In clinical practice, $\mathrm{CBF}$ maps are generally automatically generated by the manufac- 


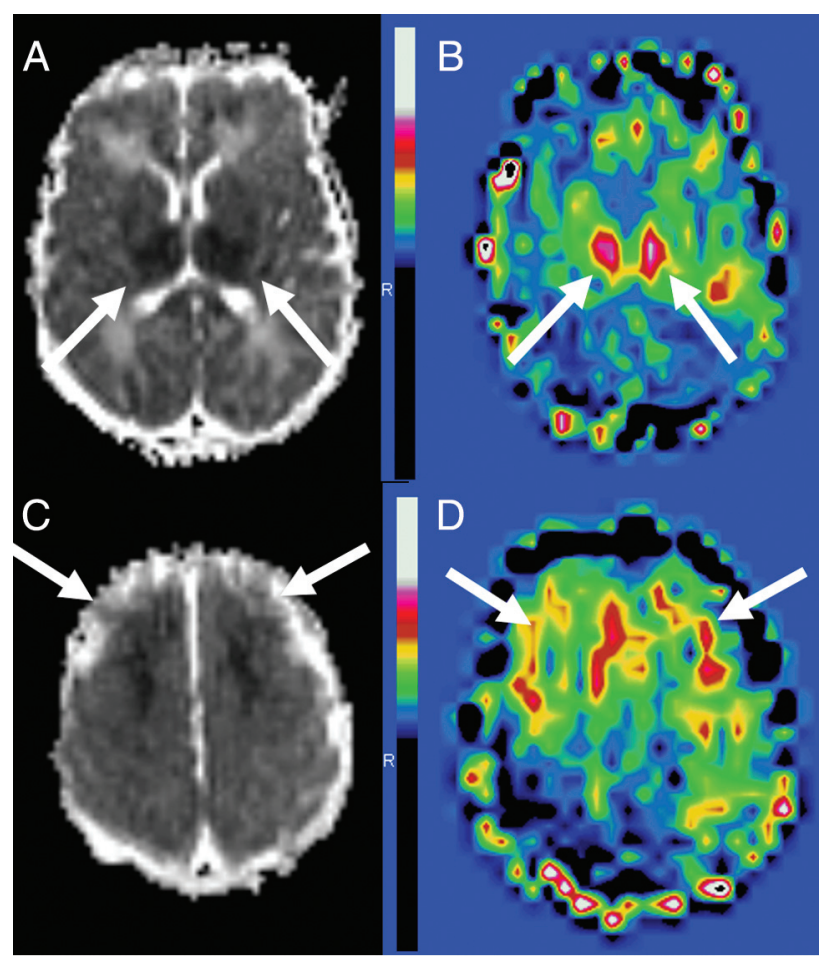

FIG 4. HIE ASL. Asphyxiated neonate treated with hypothermia showing ischemic injury on MR imaging obtained on day 3 of life. The ADC map shows restricted diffusion in the bilateral thalami and lentiform nuclei $(A)$ and in the frontal watershed areas (C) (arrows). ASL perfusion map $(B$ and $D$ ) reveals higher perfusion within the same areas (arrows).

turer workstation with assumed or measured quantification parameters.

A few studies have been conducted in neonates by using ASL. Miranda et $\mathrm{al}^{71}$ were the first to show the feasibility of pulsed ASL at $1.5 \mathrm{~T}$ in 29 unsedated healthy preterm infants at term-equivalent age and in term neonates. Other studies in healthy children show that ASL appears sensitive to regional and age-related differences in CBF in preterm, term neonates, and infants at 3 months $s^{72}$ and from 3 to 5 months of age. ${ }^{73}$ These results are consistent with previous studies demonstrating regional variation in brain maturation. Some studies have been conducted in asphyxiated neonates, showing early hyperperfusion in brain areas subsequently exhibiting injury, ${ }^{74}$ and that regions with low ADC intensity are highly correlated with co-located regions of increased ASL CBF intensity (Fig 4). ${ }^{75}$ Asphyxiated neonates treated with hypothermia developing brain injury usually displayed hypoperfusion on day of life 1 and hyperperfusion on day of life 2-3 in the study of Wintermark et al. ${ }^{74}$ If performed during the second week of life, MR imaging reveals rather a hypoperfusion in the thalamus of infants with injury on MR imaging. ${ }^{76}$ De Vis et $\mathrm{al}^{77}$ showed a significant correlation between a higher perfusion in the basal ganglia and thalami, perfusion on day of life $2-7$, and a worse neurodevelopmental outcome in neonates with HIE.

To summarize, ASL is a noninvasive method without venous cannulation or radiation that is repeatable within the same session and provides absolute quantification of CBF. Given the noninvasiveness of the technique, it is highly suitable for neonates.

\section{CONCLUSIONS}

Brain perfusion may play a role in neonatal brain injury and therefore serves as a complementary biomarker to help determine neuroprotective therapeutic strategies. With the development of noninvasive methods, assessment of neonatal brain perfusion has become easier. ASL is a very promising tool for assessing neonatal brain perfusion: It is a totally noninvasive method easily available and providing quantitative regional $\mathrm{CBF}$ values. However, the method warrants technical adjustments to make it more widely available.

\section{ACKNOWLEDGMENTS}

The authors thank Prof. Eric Guedj (CHU Timone, Marseille, France) for providing PET images and Ms Tracey Westcott for editorial assistance.

Disclosures: Maïa Proisy—RELATED: Grant: research grant 2012 Société Française de Radiologie (French Society of Radiology). Nicola J. Robertson-UNRELATED: Grants/Grants Pending: Chiesi Pharmaceutici S.p.A (research grant)*; Royalties: Chiesi, Comments: for licensing of intellectual property. *Money paid to the institution.

\section{REFERENCES}

1. Leiva-Salinas C, Provenzale JM, Kudo K, et al. The alphabet soup of perfusion CT and MR imaging: terminology revisited and clarified in five questions. Neuroradiology 2012;54:907-18 CrossRef Medline

2. Kety SS, Schmidt CF. The nitrous oxide method for the quantitative determination of cerebral blood flow in man: theory, procedure and normal values. J Clin Invest 1948;27:476-83 CrossRef Medline

3. Meier P, Zierler KL. On the theory of the indicator-dilution method for measurement of blood flow and volume. J Appl Physiol 1954;6: 731-44 Medline

4. Ostergaard L, Weisskoff RM, Chesler DA, et al. High resolution measurement of cerebral blood flow using intravascular tracer bolus passages, Part I: mathematical approach and statistical analysis. Magn Reson Med 1996;36:715-25 CrossRef Medline

5. Wintermark M, Sesay M, Barbier E, et al. Comparative overview of brain perfusion imaging techniques. Stroke 2005;36:e83-99 CrossRef Medline

6. Goff DA, Buckley EM, Durduran T, et al. Noninvasive cerebral perfusion imaging in high-risk neonates. Semin Perinatol 2010;34: 46-56 CrossRef Medline

7. Wintermark P. Injury and repair in perinatal brain injury: insights from non-invasive MR perfusion imaging. Semin Perinatol 2015;39: 124-29 CrossRef Medline

8. Volpe JJ. Neonatal encephalopathy: an inadequate term for hypoxic-ischemic encephalopathy. Ann Neurol 2012;72:156-66 CrossRef Medline

9. Gluckman PD, Wyatt JS, Azzopardi D, et al. Selective head cooling with mild systemic hypothermia after neonatal encephalopathy: multicentre randomised trial. Lancet 2005;365:663-70 CrossRef Medline

10. Shankaran S, Laptook AR, Ehrenkranz RA, et al; National Institute of Child Health and Human Development Neonatal Research Network. Whole-body hypothermia for neonates with hypoxic-ischemic encephalopathy. $N$ Engl J Med 2005;353:1574-84 CrossRef Medline

11. Faulkner S, Bainbridge A, Kato T, et al. Xenon augmented hypothermia reduces early lactate/ $\mathrm{N}$-acetylaspartate and cell death in perinatal asphyxia. Ann Neurol 2011;70:133-50 CrossRef Medline

12. Kelen D, Robertson NJ. Experimental treatments for hypoxic ischaemic encephalopathy. Early Hum Dev 2010;86:369-77 CrossRef Medline 
13. Rutherford M, Malamateniou C, McGuinness A, et al. Magnetic resonance imaging in hypoxic-ischaemic encephalopathy. Early Hum Dev 2010;86:351-60 CrossRef Medline

14. Rutherford M, Ramenghi LA, Edwards AD, et al. Assessment of brain tissue injury after moderate hypothermia in neonates with hypoxic-ischaemic encephalopathy: a nested substudy of a randomised controlled trial. Lancet Neurol 2010;9:39-45 CrossRef Medline

15. Barkovich AJ, Hajnal BL, Vigneron D, et al. Prediction of neuromotor outcome in perinatal asphyxia: evaluation of MR scoring systems. AJNR Am J Neuroradiol 1998;19:143-49 Medline

16. Alderliesten T, de Vries LS, Benders MJ, et al. MR imaging and outcome of term neonates with perinatal asphyxia: value of diffusionweighted MR imaging and ${ }^{1}$ H MR spectroscopy. Radiology 2011;261: 235-42 CrossRef Medline

17. Cheong JL, Cady EB, Penrice J, et al. Proton MR spectroscopy in neonates with perinatal cerebral hypoxic-ischemic injury: metabolite peak-area ratios, relaxation times, and absolute concentrations. AJNR Am J Neuroradiol 2006;27:1546-54 Medline

18. Volpe JJ, Herscovitch P, Perlman JM, et al. Positron emission tomography in the asphyxiated term newborn: parasagittal impairment of cerebral blood flow. Ann Neurol 1985;17:287-96 CrossRef Medline

19. Greisen G. Autoregulation of cerebral blood flow in newborn babies. Early Hum Dev 2005;81:423-28 CrossRef Medline

20. Back SA, Han BH, Luo NL, et al. Selective vulnerability of late oligodendrocyte progenitors to hypoxia-ischemia. J Neurosci 2002;22: 455-63 Medline

21. Todd MM, Weeks J. Comparative effects of propofol, pentobarbital, and isoflurane on cerebral blood flow and blood volume. J Neurosurg Anesthesiol 1996;8:296-303 CrossRef Medline

22. Harreld JH, Helton KJ, Kaddoum RN, et al. The effects of propofol on cerebral perfusion MRI in children. Neuroradiology 2013;55: 1049-56 CrossRef Medline

23. Volpe JJ, Herscovitch P, Perlman JM, et al. Positron emission tomography in the newborn: extensive impairment of regional cerebral blood flow with intraventricular hemorrhage and hemorrhagic intracerebral involvement. Pediatrics 1983;72:589-601 Medline

24. Fockele DS, Baumann RJ, Shih WJ, et al. Tc-99m HMPAO SPECT of the brain in the neonate. Clin Nucl Med 1990;15:175-77 CrossRef Medline

25. Altman DI, Powers WJ, Perlman JM, et al. Cerebral blood flow requirement for brain viability in newborn infants is lower than in adults. Ann Neurol 1988;24:218-26 CrossRef Medline

26. Chugani HT. A critical period of brain development: studies of cerebral glucose utilization with PET. Prev Med 1998;27:184-88 CrossRef Medline

27. Shi Y, Zhao JN, Liu L, et al. Changes of positron emission tomography in newborn infants at different gestational ages, and neonatal hypoxic-ischemic encephalopathy. Pediatr Neurol 2012;46:116-23 CrossRef Medline

28. Batista CE, Chugani HT, Juhász C, et al. Transient hypermetabolism of the basal ganglia following perinatal hypoxia. Pediatr Neurol 2007;36:330-33 CrossRef Medline

29. Børch K, Greisen G. 99mTc-HMPAO as a tracer of cerebral blood flow in newborn infants. J Cereb Blood Flow Metab 1997;17:448-54 Medline

30. Greisen G. Cerebral blood flow in preterm infants during the first week of life. Acta Paediatr Scand 1986;75:43-51 CrossRef Medline

31. Chiron C, Raynaud C, Mazière B, et al. Changes in regional cerebral blood flow during brain maturation in children and adolescents. J Nucl Med 1992;33:696-703 Medline

32. Pryds O, Greisen G. Effect of PaCO2 and haemoglobin concentration on day to day variation of CBF in preterm neonates. Acta Paediatr Scand Suppl 1989;360:33-36 Medline

33. Tokumaru AM, Barkovich AJ, O'uchi T, et al. The evolution of cerebral blood flow in the developing brain: evaluation with iodine-123 iodoamphetamine SPECT and correlation with MR imaging. AJNR Am J Neuroradiol 1999;20:845-52 Medline

34. Eastwood JD, Lev MH, Provenzale JM. Perfusion CT with iodinated contrast material. AJR Am J Roentgenol 2003;180:3-12 CrossRef Medline

35. Wintermark M, Cotting J, Roulet E, et al. Acute brain perfusion disorders in children assessed by quantitative perfusion computed tomography in the emergency setting. Pediatr Emerg Care 2005;21: 149-60 Medline

36. Wintermark M, Lepori $\mathrm{D}$, Cotting $\mathrm{J}$, et al. Brain perfusion in children: evolution with age assessed by quantitative perfusion computed tomography. Pediatrics 2004;113:1642-52 CrossRef Medline

37. Jöbsis FF. Noninvasive, infrared monitoring of cerebral and myocardial oxygen sufficiency and circulatory parameters. Science 1977; 198:1264-67 CrossRef Medline

38. Wyatt JS, Cope M, Delpy DT, et al. Quantification of cerebral oxygenation and haemodynamics in sick newborn infants by near infrared spectrophotometry. Lancet 1986;2:1063-66 Medline

39. Edwards AD, Wyatt JS, Richardson C, et al. Cotside measurement of cerebral blood flow in ill newborn infants by near infrared spectroscopy. Lancet 1988;2:770-71 Medline

40. Meek JH, Tyszczuk L, Elwell CE, et al. Low cerebral blood flow is a risk factor for severe intraventricular haemorrhage. Arch Dis Child Fetal Neonatal Ed 1999;81:F15-18 CrossRef Medline

41. Roche-Labarbe N, Carp SA, Surova A, et al. Noninvasive optical measures of $\mathrm{CBV}, \mathrm{StO}(2), \mathrm{CBF}$ index, and $\mathrm{rCMRO}(2)$ in human premature neonates' brains in the first six weeks of life. Hum Brain Mapp 2010;31:341-52 CrossRef Medline

42. Tsuji M, Saul JP, du Plessis A, et al. Cerebral intravascular oxygenation correlates with mean arterial pressure in critically ill premature infants. Pediatrics 2000;106:625-32 CrossRef Medline

43. Wong FY, Leung TS, Austin T, et al. Impaired autoregulation in preterm infants identified by using spatially resolved spectroscopy. Pediatrics 2008;121:e604-11 CrossRef Medline

44. Meek JH, Elwell CE, McCormick DC, et al. Abnormal cerebral haemodynamics in perinatally asphyxiated neonates related to outcome. Arch Dis Child Fetal Neonatal Ed 1999;81:F110-15 CrossRef Medline

45. Toet MC, Lemmers PM, van Schelven LJ, et al. Cerebral oxygenation and electrical activity after birth asphyxia: their relation to outcome. Pediatrics 2006;117:333-39 CrossRef Medline

46. Zaramella P, Saraceni E, Freato F, et al. Can tissue oxygenation index (TOI) and cotside neurophysiological variables predict outcome in depressed/asphyxiated newborn infants? Early Hum Dev 2007;83: 483-89 CrossRef Medline

47. Wintermark P, Hansen A, Warfield SK, et al. Near-infrared spectroscopy versus magnetic resonance imaging to study brain perfusion in newborns with hypoxic-ischemic encephalopathy treated with hypothermia. Neuroimage 2014;85:287-93 CrossRef Medline

48. Singh H, Cooper RJ, Wai Lee C, et al. Mapping cortical haemodynamics during neonatal seizures using diffuse optical tomography: a case study. Neuroimage Clin 2014;5:256-65 CrossRef Medline

49. Kehrer M, Krägeloh-Mann I, Goelz R, et al. The development of cerebral perfusion in healthy preterm and term neonates. Neuropediatrics 2003;34:281-86 CrossRef Medline

50. Kehrer M, Goelz R, Krägeloh-Mann I, et al. Measurement of volume of cerebral blood flow in healthy preterm and term neonates with ultrasound. Lancet 2002;360:1749-50 CrossRef Medline

51. Ehehalt S, Kehrer M, Goelz R, et al. Cerebral blood flow volume measurements with ultrasound: interobserver reproducibility in preterm and term neonates. Ultrasound Med Biol 2005;31:191-96 CrossRef Medline

52. Ilves P, Lintrop M, Talvik I, et al. Developmental changes in cerebral and visceral blood flow velocity in healthy neonates and infants. $J$ Ultrasound Med 2008;27:199-207 Medline

53. Kehrer M, Schöning M. A longitudinal study of cerebral blood flow 
over the first 30 months. Pediatr Res 2009;66:560-64 CrossRef Medline

54. Eyding J, Wilkening W, Postert T. Brain perfusion and ultrasonic imaging techniques. Eur J Ultrasound 2002;16:91-104 CrossRef Medline

55. Kiselev VG. On the theoretical basis of perfusion measurements by dynamic susceptibility contrast MRI. Magn Reson Med 2001;46: 1113-22 CrossRef Medline

56. Huisman TA, Sorensen AG. Perfusion-weighted magnetic resonance imaging of the brain: techniques and application in children. Eur Radiol 2004;14:59-72 CrossRef Medline

57. Tanner SF, Cornette L, Ramenghi LA, et al. Cerebral perfusion in infants and neonates: preliminary results obtained using dynamic susceptibility contrast enhanced magnetic resonance imaging. Arch Dis Child Fetal Neonatal Ed 2003;88:F525-30 CrossRef Medline

58. Wintermark P, Moessinger AC, Gudinchet F, et al. Perfusionweighted magnetic resonance imaging patterns of hypoxic-ischemic encephalopathy in term neonates. J Magn Reson Imaging 2008; 28:1019-25 CrossRef Medline

59. Wintermark P, Moessinger AC, Gudinchet F, et al. Temporal evolution of MR perfusion in neonatal hypoxic-ischemic encephalopathy. J Magn Reson Imaging 2008;27:1229-34 CrossRef Medline

60. Varela M, Groves AM, Arichi T, et al. Mean cerebral blood flow measurements using phase contrast MRI in the first year of life. NMR Biomed 2012;25:1063-72 CrossRef Medline

61. Benders MJ, Hendrikse J, De Vries LS, et al. Phase-contrast magnetic resonance angiography measurements of global cerebral blood flow in the neonate. Pediatr Res 2011;69:544-47 CrossRef Medline

62. Ferré JC, Bannier E, Raoult H, et al. Arterial spin labeling (ASL) perfusion: techniques and clinical use. Diagn Interv Imaging 2013; 94:1211-23 CrossRef Medline

63. Alsop DC, Detre JA, Golay X, et al. Recommended implementation of arterial spin-labeled perfusion MRI for clinical applications: a consensus of the ISMRM perfusion study group and the European consortium for ASL in dementia. Magn Reson Med 2015;73:102-16 CrossRef Medline

64. Boudes E, Gilbert G, Leppert IR, et al. Measurement of brain perfusion in newborns: pulsed arterial spin labeling (PASL) versus pseudo-continuous arterial spin labeling (pCASL). Neuroimage Clin 2014;6:126-33 CrossRef Medline

65. Wang J, Licht DJ, Jahng G-H, et al. Pediatric perfusion imaging using pulsed arterial spin labeling. J Magn Reson Imaging 2003;18: 404-13 CrossRef Medline
66. Madan N, Grant PE. MR perfusion imaging in pediatrics. In Barker PB, Golay X, Zaharchuk G, eds. Clinical Perfusion MRI: Techniques and Applications. Cambridge: Cambridge University Press; 2013:326-48

67. Kehrer M, Blumenstock G, Ehehalt S, et al. Development of cerebral blood flow volume in preterm neonates during the first two weeks of life. Pediatr Res 2005;58:927-30 CrossRef Medline

68. Ferré JC, Petr J, Barillot C, et al. Optimal individual inversion time in brain arterial spin labeling perfusion magnetic resonance imaging: correlation with carotid hemodynamics measured with cine phasecontrast magnetic resonance imaging. J Comput Assist Tomogr 2013; 37:247-51 CrossRef Medline

69. Wu WC, St. Lawrence KS, Licht DJ, et al. Quantification issues in arterial spin labeling perfusion magnetic resonance imaging. Top Magn Reson Imaging 2010;21:65-73 CrossRef Medline

70. Varela M, Hajnal JV, Petersen ET, et al. A method for rapid in vivo measurement of blood T1. NMR Biomed 2011;24:80-88 CrossRef Medline

71. Miranda MJ, Olofsson K, Sidaros K. Noninvasive measurements of regional cerebral perfusion in preterm and term neonates by magnetic resonance arterial spin labeling. Pediatr Res 2006;60:359-63 CrossRef Medline

72. De Vis JB, Petersen ET, de Vries LS, et al. Regional changes in brain perfusion during brain maturation measured non-invasively with arterial spin labeling MRI in neonates. Eur J Radiol 2013;82:538-43 CrossRef Medline

73. Duncan AF, Caprihan A, Montague EQ, et al. Regional cerebra blood flow in children from 3 to 5 months of age. AJNR Am J Neuroradiol 2014;35:593-98 CrossRef Medline

74. Wintermark $\mathrm{P}$, Hansen $\mathrm{A}$, Gregas $\mathrm{MC}$, et al. Brain perfusion in asphyxiated newborns treated with therapeutic hypothermia. AJNR Am J Neuroradiol 2011;32:2023-29 CrossRef Medline

75. Pienaar R, Paldino MJ, Madan N, et al. A quantitative method for correlating observations of decreased apparent diffusion coefficient with elevated cerebral blood perfusion in newborns presenting cerebral ischemic insults. Neuroimage 2012;63:1510-18 CrossRef Medline

76. Massaro AN, Bouyssi-Kobar M, Chang T, et al. Brain perfusion in encephalopathic newborns after therapeutic hypothermia. AJNR Am J Neuroradiol 2013;34:1649-55 CrossRef Medline

77. De Vis JB, Hendrikse J, Petersen ET, et al. Arterial spin-labelling perfusion MRI and outcome in neonates with hypoxic-ischemic encephalopathy. Eur Radiol 2015;25:113-21 CrossRef Medline 